\title{
New classification of foaming agents for fire extinguishing
}

\author{
Evgeniy Degaev ${ }^{1, *}$ \\ ${ }^{1}$ Moscow State University of Civil Engineering", Yaroslavskoe shosse 26, 129337, Moscow, Russia
}

\begin{abstract}
Extinguishing fires of petroleum products during emergency spill at industrial facilities of capital construction, transport, gas stations and the destruction of oil tanks is most effective when using foamers. Classification of foaming agents intended for extinguishing of fires of oil products, which is based on the structure of spreading coefficient of water foam-forming solution over hydrocarbon surface is presented. Results of experimental studies using various foaming agents with different structure of spreading coefficient are given. It is determined which of homologs of a number of sodium primary alkylsulfates differ in foaming capacity and fire extinguishing efficiency. It is revealed that decrease of interfacial tension value leads to reduction of extinguishing time of a heptane flame.
\end{abstract}

\section{Introduction}

Due to the high fire danger for oil-storage tank farms topical theme is the development of new tools and ways of petroleum products fire suppression. Since the heat flow from the burning tank does not allow to approach close to the burning object, the main way to extinguish fires of petroleum products is supply of foam of low expansion. To prevent foam from mixing with petroleum products, when falling from a high altitude, directly on the burning surface, foaming agents are used, which aqueous solutions have a particularly low interracial tension.

The regulatory documents state the requirement for a working solution of a foaming agent, on the basis of which a foam is obtained, in terms of interracial tension - no more than $17.3 \mathrm{mN} / \mathrm{m}$ and interfacial - not less than $2.5 \mathrm{mN} / \mathrm{m}$, while it is expected that spreading of the aqueous solution on heptane coefficient should not fall below $0.3 \mathrm{mN} / \mathrm{m}$.

There is no analysis of the impact of the components in scientific literature that define the spreading of the aqueous solution on heptane coefficient per extinguishing efficiency of low expansion foam, as well as the effect of the foam expansion, altitude of its fall and the way foam is supplied into the tank base on the extinguishing efficiency.

The most obvious factor that ensures the extinguishing efficiency of the foam is the surface activity of the aqueous solution at the junction with the oil product.

The current classification of foaming agents for extinguishing fire of petroleum products is determined by several regulatory documents. As a rule, the division of foaming agents by chemical nature is provided. Consumers are challenged in the chemical essence of the

\footnotetext{
* Corresponding author: degaev@inbox.ru
} 
foaming agent, especially since typically the manufacturer keeps the composition of the components of the foaming agent secret. Ultimately, consumers are interested in extinguishing and foaming properties of the foaming agent .

These properties are determined by the surface activity of the aqueous solution at the junction with air and oil product. Therefore, we can try to create a classification of foaming agents without their chemical structure.

The purpose of this work is to develop a classification of foaming agents dedicated for extinguishing fires of petroleum products due to spreading of the aqueous solution on hydrocarbon surface coefficient, based on complex investigational studies of foam extinguishing effectiveness and surface activity at the junction with a hydrocarbon [1-6].

\section{Materials and Methods}

Version of foaming agent classification for extinguishing fire of petroleum products is based on the second law of thermodynamics, whereby the spontaneous behavior is contingent upon decrease in free energy of the system. In the case of the formation of an aqueous film on the surface of hydrocarbons, the change in free energy is due to a decrease in interfacial energy in system "hydrocarbon - aqueous solution - phase boundary - film - hydrocarbon". If we do not take into account the thickness of the aqueous film in film-hydrocarbon system, then changing the surface energy of a system can be expressed as a difference corresponding to the values of the interracial tension and the phase boundary between the film and the hydrocarbon, according to a known formula, and estimated upon the value of $f_{\sigma(01)}$-spreading of solution on hydrocarbon coefficient [5-9]:

$$
f_{\sigma(01)}=\sigma_{1}-\left(\sigma_{10}+\sigma_{0}\right),
$$

where $\sigma_{1}$ - is the superficial tension of heptane, $\mathrm{mN} / \mathrm{m} ; \sigma_{10}-$ is the interracial tension at solution-heptane junction, $\mathrm{mN} / \mathrm{m} ; \sigma_{0}$ - is the superficial tension of an aqueous-based, $\mathrm{mN} / \mathrm{m}$.

Judging by the expression of the formula, the structure of the spreading coefficient is characterized by the components: where $\sigma_{0}, \sigma_{1}$ and $\sigma_{10}$ - interracial tension of aqueous solution, flammable liquid and solution-hydrocarbon junction respectively.

The proposed variant for the classification of foaming agents for extinguishing fire of petroleum products according to the structure of spreading coefficient of working, aqueous solution on hydrocarbon includes six groups.

1. $f_{\sigma(01)}$ - positive; $f_{\sigma(01)}<f_{\sigma(10)} ; \sigma_{10} \geq 2.5 \mathrm{mN} / \mathrm{m}$, fluorinated, effective with a sublayer supply to the oil, forms an equilibrium aqueous film on the hydrocarbon, characterized by a long period of burnback from an open flame source.

2. $f_{\sigma(01)}$ - positive; $f_{\sigma(01)}<f_{\sigma(10)} ; \sigma_{10}<2.5 \mathrm{mN} / \mathrm{m}$ fluorinated complex, requires an increased specific consumption of the solution during sublayer supply to the oil.

3. $f_{\sigma(01)}$ - negative; $f_{\sigma(01)}<f_{\sigma(10)} ; \sigma_{10}>2.5 \mathrm{mN} / \mathrm{m}$, fluorinated, effective at sublayer supply into the oil product, but does not form an equilibrium aqueous film on the hydrocarbon. Long isolating effect.

4. $f_{\sigma(01)}$ - negative; $f_{\sigma(01)} \gg f_{\sigma(10)} ; \sigma_{10} \gg>2.5 \mathrm{mN} / \mathrm{m}$, hydrocarbon extinguishing by "careful" foam supply.

5. $f_{\sigma(01)}$ - negative; $f_{\sigma(01)}>f_{\sigma(10)} ; \sigma_{10} \geq 2.5 \mathrm{mN} / \mathrm{m}$, hydrocarbon complex, the foam based on it should be supplied to the tank shell. Characterized by increased foam elasticity.

The magnitude of interfacial tension $2.5 \mathrm{mN} / \mathrm{m}$, adopted as a threshold value, found by measurement and, previously, incorporated into regulatory documents [10-17]. 


\section{Results}

On the basis of the proposed version of the classification, investigational studies have been carried out sequentially using foaming agents corresponding to the above groups and differing in the structure of the spreading coefficient.

Individual and mixed hydrocarbon surface-active materials were used as foaming agents. Most of the known hydrocarbon foaming agents have primary sodium alkyl sulfates. The studies were carried out using individual homologues of a number of primary sodium alkyl sulfates, including hexyl sulfate, octyl sulfate, decyl sulfate, dodecylsulfate (laurylsulfate) and a mixture of dodecyl and tetradecyl sulfates, a mixture of tetradecyl sulfate and sodium octadecyl sulfate. It was necessary to elucidate which of the homologues has foaming capacity and extinguishing efficiency. The results of investigational studies are shown in Fig. 1-6.

According to the extinguishing efficiency, solutions of sodium dodecylsulfate (laurylsulfate), having interracial tension at the air junction, and increased interfacial tension at the heptane junction, are distinguished. A special behavior feature of the of alkyl sulfates is the presence of a positive spreading coefficient of the hydrocarbon in the foam/water mixture. In this case spreading coefficient of the hydrocarbon in the foam/water mixture is $f_{\sigma(10)}$ is calculated by formula (2):

$$
f_{\sigma(10)}=\sigma_{0}-\left(\sigma_{10}+\sigma_{1}\right)
$$

Structure of spreading coefficient $f_{\sigma(10)}$ is characterized by the same elements: where $\sigma_{0}$, $\sigma_{1}$ and $\sigma_{10}-$ interracial tension of aqueous solution, flammable liquid and solutionhydrocarbon junction respectively.

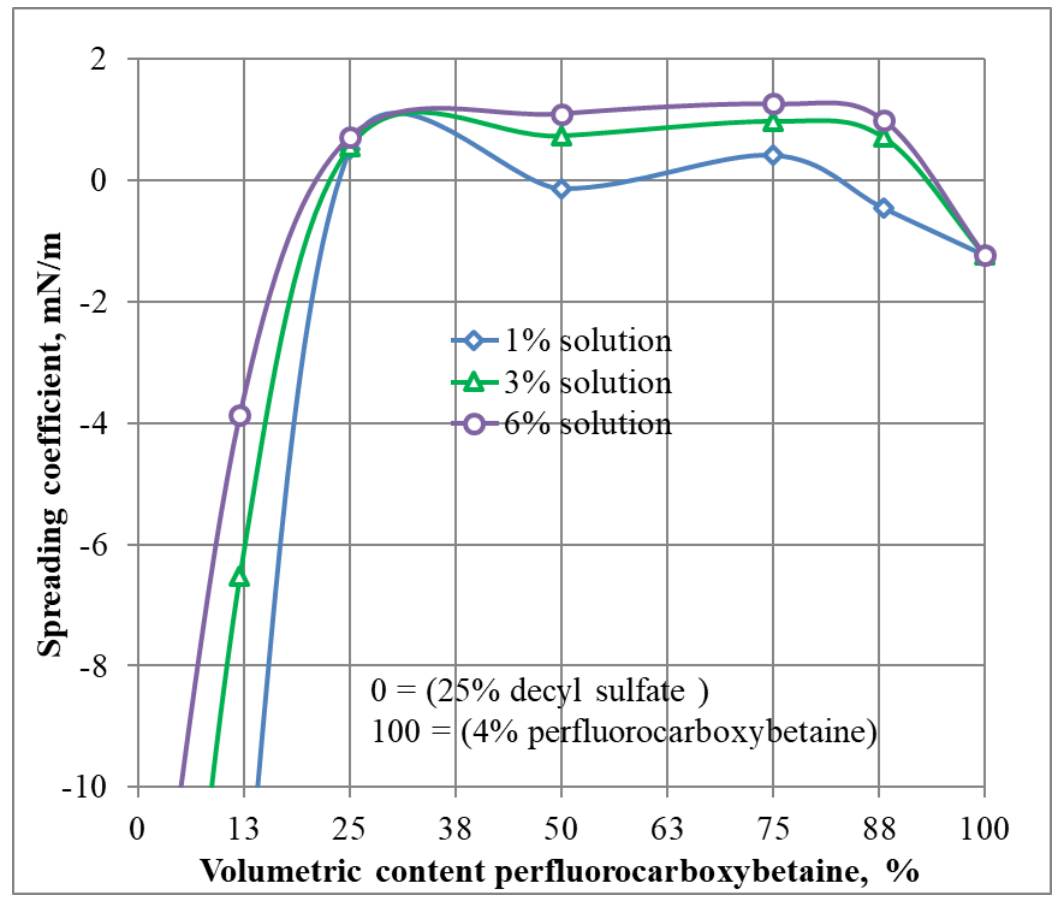

Fig. 1. Spreading of the aqueous solution on heptane coefficient in system "sodium decyl sulfate perfluorocarboxybetaine". The concentration of working solutions is shown in the figure. 


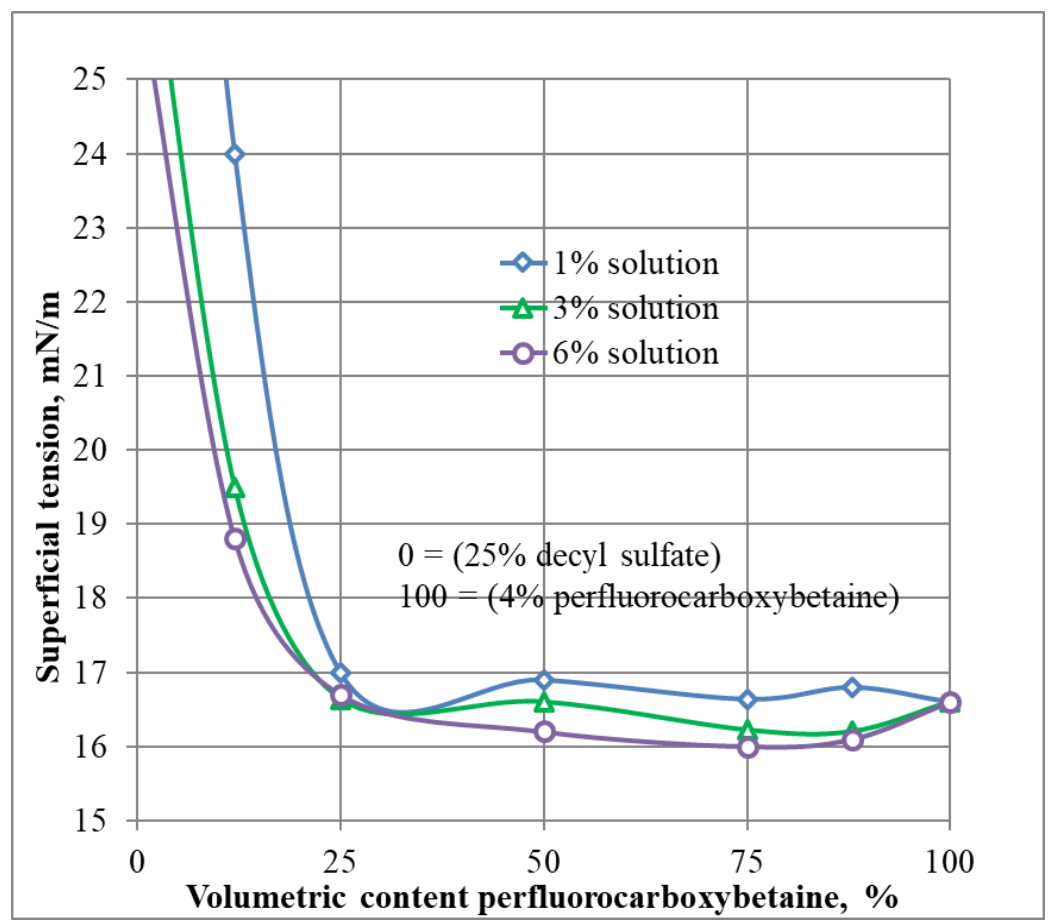

Fig. 2. Interracial tension of the aqueous solution on the junction with air in system "sodium decyl sulfate - perfluorocarboxybetaine". The concentration of working solutions is shown in the figure.

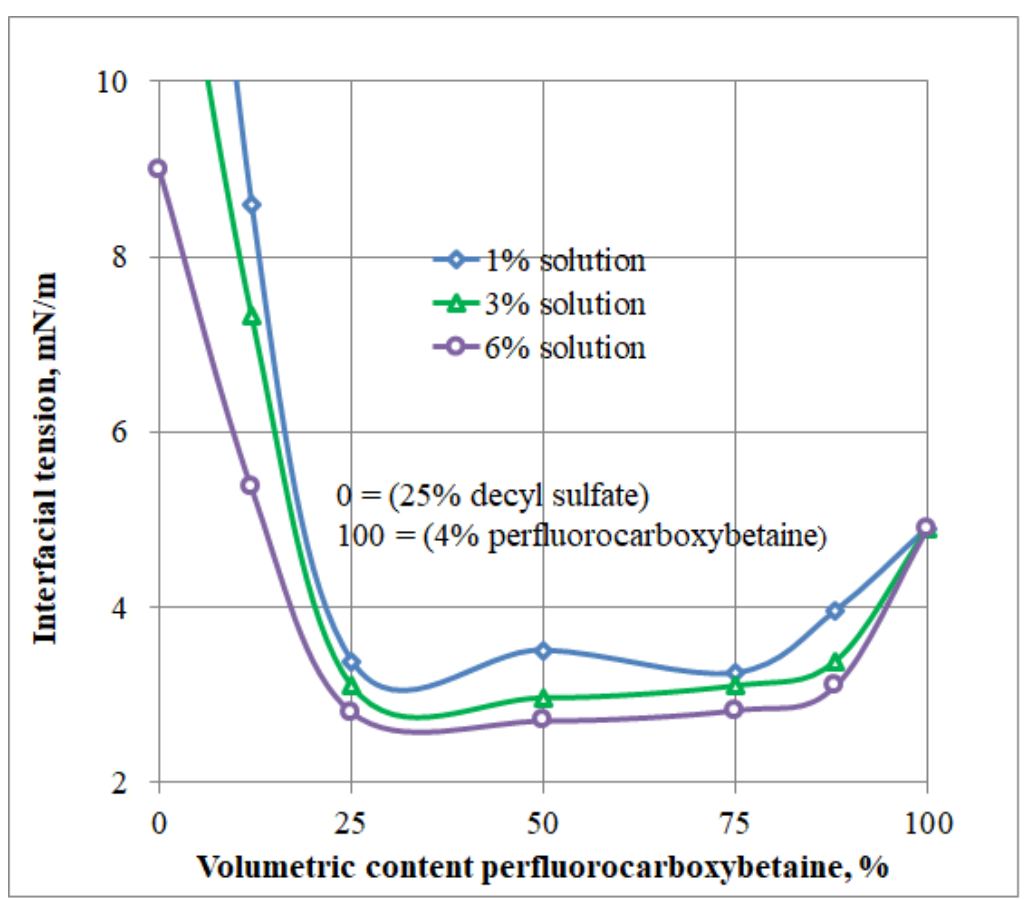

Fig. 3. Interfacial tension of the aqueous solution on the junction with heptane in system "sodium decyl sulfate - perfluorocarboxybetaine". The concentration of working solutions is shown in the figure. 


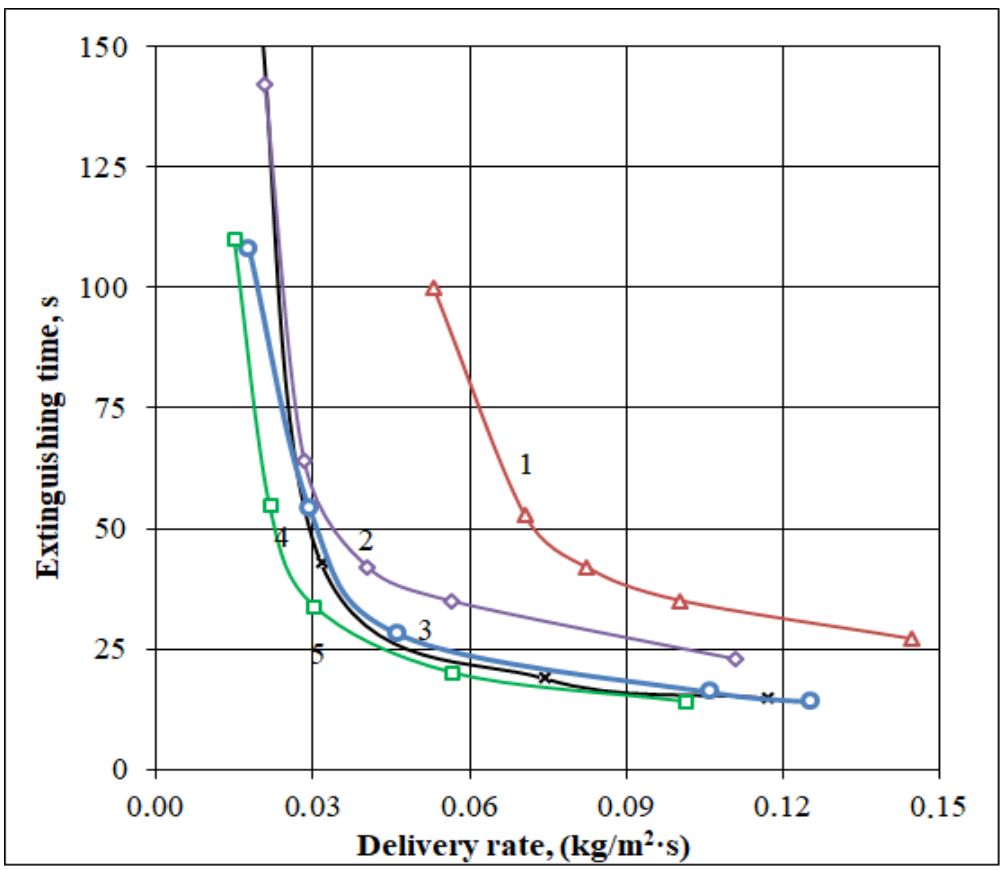

Fig. 4. The dependence of the extinguishing time for the heptane flame on the foam application rate derived from working solutions with different spreading coefficients: $1 . f_{\sigma(01)}=-1.0 \mathrm{~m} / \mathrm{m} ; 2 . f_{\sigma(01)}=-$ $0.5 \mathrm{mN} / \mathrm{m} ; 3 . f_{\sigma(01)}=0.5 \mathrm{mN} / \mathrm{m} ; 4 . f_{\sigma(01)}=1.0 \mathrm{mN} / \mathrm{m} ; 5 . f_{\sigma(01)}=1.3 \mathrm{mN} / \mathrm{m}$.

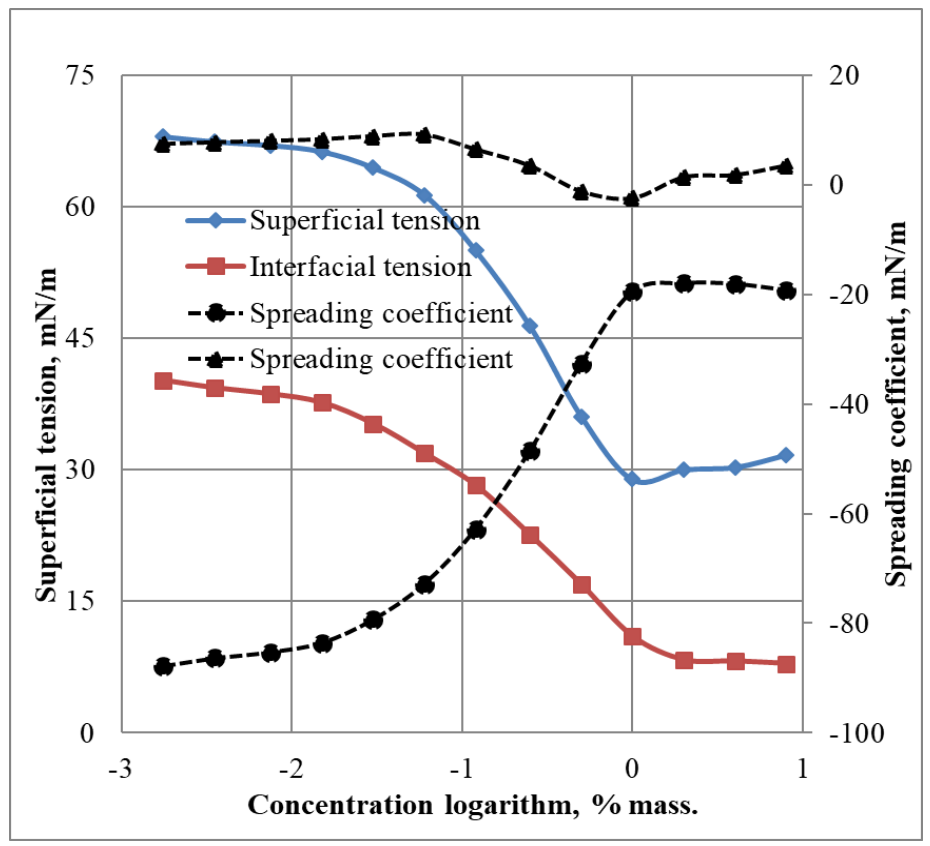

Fig. 5. Isotherms of interracial tension and spreading coefficient of foam solution - sodium alkyl sulfate, fraction C8-C10. Refers to the first classification group: $f_{\sigma(01)}$ - negative; $f_{\sigma(01)}>f_{\sigma(01)} ; \sigma_{10} \geq 2.5$ $\mathrm{mN} / \mathrm{m}$. 


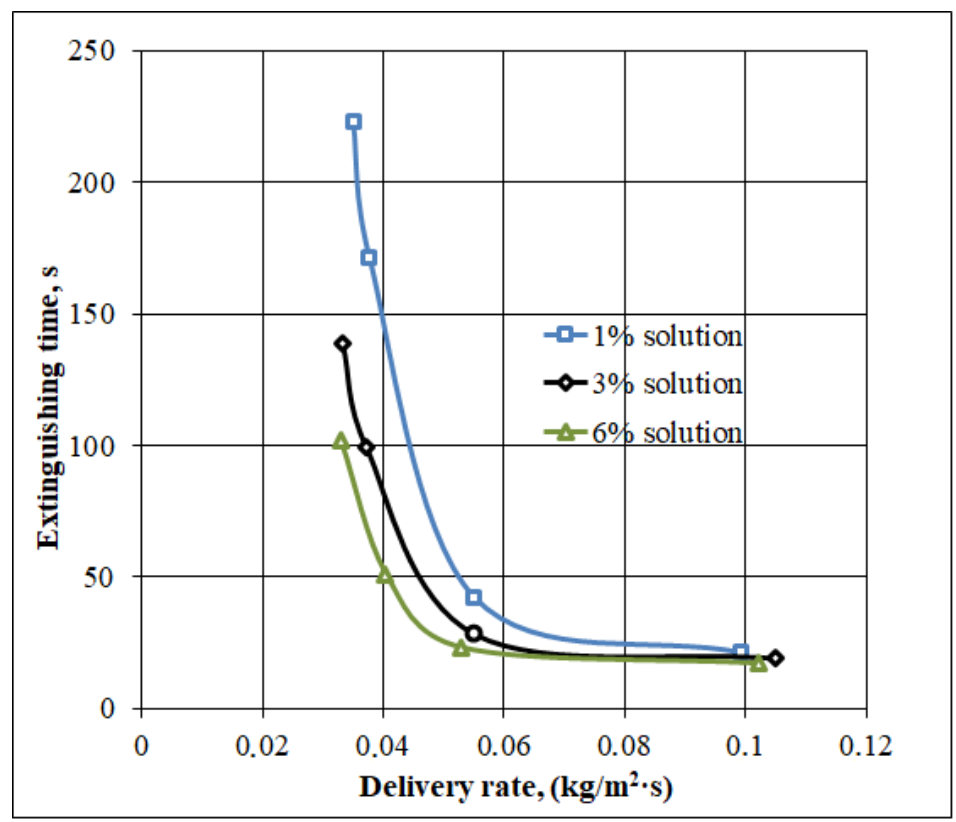

Fig. 6. Effect of foaming agent concentration - sodium alkyl sulfate, fraction $\mathrm{C} 8-\mathrm{C} 10$, on the dependence of the extinguishing time and specific flow rate on the rate of solution application, when the foam is supplied to the burning surface of heptane. Foaming agent refers to the first classification group.

\section{Conclusions}

The complex investigational studies of extinguishing efficiency of foam and the surface activity of working solutions obtained from solutions of various foaming agents have shown the possibility of separating foaming agents in accordance with the proposed classification based on an structural analysis of spreading of the foaming agent working solution on heptane coefficient [18-20].

\section{References}

1. V.I. Blinov, G.N. Khudyakov, Diffusion burning of liquids (Russian Academy of Sciences Publ., Moscow, 1961)

2. D.A. Korolchenko, E.N. Degaev, A.F. Sharovarnikov, 2nd International conference on material engineering and application, DOI 10.12783/dtmse/icmea2015/7238

3. A.F. Sharovarnikov, S.S. Voevoda, V.P. Molchanov, Modern means and methods for extinguishing oil fires (Kalan, Moscow, 2000)

4. A.F. Sharovarnikov, G.I. Punchik, Colloid Journal 44-1, 180 (1982)

5. C. Jho, Journal of Colloid and Interface Science 117-1, 138-148 (1987)

6. T. Shaefer, B. Dlugogorski, E. Kennedy, Sealability Properties of Fluo-rine-Free Fire Fighting Foams (University of Newcastle, 2007)

7. N. Nurimoto, Fire extinguishing installations for oil storages injecting foam under the layer of oil product 27-3, 11-19 (1977) 
8. V.G. Borkovskaya, Advanced Materials Research 945-949, 3012-3015 (2014) DOI: 10.4028/www.scientific.net/AMR.945-949.3012

9. V.G. Borkovskaya, Applied Mechanics and Materials 467, 287-290 (2014) DOI: 10.4028/www.scientific.net/AMM.467.287

10. B.G. Borkovskaya, C.V. Agapov, Fire and Explosion Safety 23-11, 7-14 (2014)

11. V.G. Borkovskaya, Fire and Explosion Safety 22-12, 9-15 (2013)

12. V.G. Borkovskaya, Engineering Management 457-476-15, 1703-1706 (2013) DOI: 10.4028/www.scientific.net/AMM.475-476.1703

13. Z.M. Xiang, M.L. Guang, L. Chao, International Conference on Intelligent Manufacturing and Materials (2016) DOI: 10.12783/dtmse/icimm2016/6244

14. I. Turekova, K. Balog, M. Polka, Bezpieczenstwo i Technika Pozarnicza 25, 29-36 (2012)

15. D.A. Korolchenko, A.F. Sharovarnikov, E.N. Degaev, Patent 2579730. Russian Federation, A62C3/06. Method to Extinguish Fire Emergencies of Petroleum and Products in Tanks with Pontoons or Floating Roof, by Supplying Foam to Tank Base

16. D.A. Korolchenko, A.F. Sharovarnikov, E.N. Degaev, Patent 2589613. Russian Federation, A62C3/00. Method to Extinguish Fire Emergencies of Petroleum and Products by Preventing Tank Overheating by Torch Flame

17. V.G. Borkovskaya, Engineering Education 860-863-26, 3009-3012 (2013) DOI: 10.4028/www.scientific.net/AMR.860-863.3009

18. B.G. Borkovskaya, E.N. Degaev, Real estate: economics, management 1, 21-25 (2018)

19. D.A. Korolchenko, E.N. Degaev, A.F. Sharovarnikov, 2nd International conference on material engineering and application, 17-22 (2015) DOI: 10.12783/dtmse/icmea2015/7237

20. E.N. Degaev, D.A. Korolchenko, MATEC Web of Conferences 26, 00036 (2017) DOI: $10.1051 /$ matecconf/201711700036 